\title{
The feasibility and validity of a preference- weighted composite endpoint to establish value in geriatric care
}

\author{
Cynthia Hofman ${ }^{1,2^{*}}$, Jennifer Lutomski ${ }^{1}$, Han Boter ${ }^{3}$, Bianca Buurman ${ }^{4}$, Ton De Craen ${ }^{5}$, Marcel OldeRikkert ${ }^{1}$, \\ Rogier Donders ${ }^{2}$, Peter Makai ${ }^{1}$, René Melis ${ }^{1}$
}

From Health Services Research: Evidence-based practice

London, UK. 1-3 July 2014

\section{Background}

As part of the Dutch National Care for the Elderly Programme, The Older Persons and Informal Caregivers Survey Minimum Data Set (TOPICS-MDS) was developed to gather uniform information on outcome measures. Furthermore, to combine the outcome measures into one single index and to promote comparability between studies, a preference-weighted Composite End Point (called: TOPICS-CEP) was developed [1]. The aim of this study was to validate TOPICS-CEP in a large heterogeneous sample of older persons aged $\geq 65$ years.

\section{Materials and methods}

Data from 17,603 older persons were derived from TOPICS-MDS (www.TOPICS-MDS.eu); a public data repository. Feasibility was evaluated by the prevalence of missing values among TOPICS-CEP scores. To assess convergent validity, TOPICS-CEP scores were cross validated against the Cantril's ladder life satisfaction scale and the EuroQol-5D utility score. Known-group validity of TOPICS-CEP was investigated across socio-demographic and clinical characteristics. To assess whether TOPICS-CEP scores were generalizeble across different settings, we conducted pooled and subgroup analyses: older persons in the general population, general practitioner setting, and hospital.

\section{Results}

In the complete sample, TOPICS-CEP scores could be calculated for the majority of the participants $(88.7 \%)$. There were no floor and ceiling effects found and the

${ }^{1}$ Geriatric Medicine, Radboud University Medical Center, Nijmegen, The Netherlands

Full list of author information is available at the end of the article distribution was slightly skewed to the left. The correlation between TOPICS-CEP and Cantril's ladder was 0.43 (95\% CI [0.39-0.48]) and the correlation between TOPICS-CEP and EuroQol-5D was 0.63 (95\%CI [0.580.67]). Expectedly, mean TOPICS-CEP scores differed significantly $(\mathrm{p}<0.05)$ across marital status (married or cohabiting: 7.50 versus partner deceased: 7.13 ), living arrangements (independent living with others: 7.56 versus dependent living: 6.37), dementia (no: 7.43 versus yes: 6.30), depression (no: 7.42 versus yes: 6.26 ), and dizziness with falls (no: 749 versus yes: 6.42). When stratified by subgroups, similar results were found for feasibility, convergent and known-group validity.

\section{Conclusions}

The TOPICS-CEP was able to accurately reflect general wellbeing in a large pooled dataset as well as across subgroups. Our data support that the TOPICS-CEP score is an objective and robust measure for researchers interested in investigating the general well-being of older persons. The TOPICS-CEP guideline version 1.1 is now available online http://www.TOPICS-MDS.eu.

\section{Authors' details \\ ${ }^{1}$ Geriatric Medicine, Radboud University Medical Center, Nijmegen, The Netherlands. ${ }^{2}$ Health Evidence, Radboud University Medical Center, Nijmegen, The Netherlands. ${ }^{3}$ Epidemiology, University Medical Centre Groningen, Groningen, The Netherlands. ${ }^{4}$ Internal Medicine and Geriatrics, Academic Medical Center, Amsterdam, The Netherlands. ${ }^{5}$ Gerontology and Geriatrics, Leiden University Medical Centre, Leiden, The Netherlands.}

Published: 7 July 2014

\section{Reference}

1. Hofman CS, Makai P, Buurman BM, de Craen AJM, Boter H, OldeRikkert MGM, Donders ART, Melis RJF: Establishing a composite 
endpoint for measuring the effectiveness of geriatric interventions based on older persons' and informal caregivers' preference weights: A vignette study. BMC Geriatrics 2014, 14:51.

doi:10.1186/1472-6963-14-S2-P55

Cite this article as: Hofman et al:: The feasibility and validity of a

preference-weighted composite endpoint to establish value in geriatric

care. BMC Health Services Research 2014 14(Suppl 2):P55.

Submit your next manuscript to BioMed Central and take full advantage of:

- Convenient online submission

- Thorough peer review

- No space constraints or color figure charges

- Immediate publication on acceptance

- Inclusion in PubMed, CAS, Scopus and Google Scholar

- Research which is freely available for redistribution

Submit your manuscript at www.biomedcentral.com/submit 